\title{
Explorando a interatividade no Planeta ROODA 2.0
}

\author{
Ana Carolina Ribeiro Ribeiro \\ Bernardo Frederes Krämer Alcalde \\ Patricia Alejandra Behar
}
Faculdade de Educação (FACED)/Núcleo de Tecnologia Digital aplicada à Educação
(NUTED) - Universidade Federal do Rio Grande do Sul (UFRGS)
Porto Alegre - RS - Brasil

carol_ribeiro2@hotmail.com, bernardoalcalde@gmail.com, pbehar@terra.com.br

Resumo: O presente artigo tem por objetivo apresentar a reformulação de um Ambiente Virtual de Aprendizagem (AVA), o Planeta ROODA 2.0, destinado a crianças da Educação Infantil e Ensino Fundamental. Essa reformulação mostrou-se necessária para congregar os paradigmas identificados na atual configuração das redes virtuais, a denominada Web 2.0. Esse projeto vem sendo desenvolvido desde 2008 por um Núcleo interdisciplinar e está sendo validado no presente semestre em um curso de extensão destinado a professores dos diferentes níveis de ensino.

Palavras-chave: Ambiente Virtual de Aprendizagem, Web 2.0, Planeta ROODA, Ensino Fundamental.

Abstract: This article's main aim is to present a reformulation of Planeta ROODA, a Virtual Learning Environment focused on children. The developing of Planeta ROODA 2.0 was based on the needing of include the Web 2.0 concepts to the Environment. This project has been developed since 2008 by a multidisciplinary team and its validating is being reached on this semester through an extension course targeted to teachers from different teaching levels.

Keywords: Virtual Learning Environment, Web 2.0, Planeta ROODA, basic education.

\section{Introdução}

O presente artigo busca apresentar a reformulação de um Ambiente Virtual de Aprendizagem (AVA), O Planeta ROODA 2.0, destinado a crianças da Educação Infantil e Ensino Fundamental. Essa reformulação mostrou-se necessária para congregar os paradigmas identificados na atual configuração das redes virtuais, a denominada Web 2.0. Busca-se, com isso, transgredir os limites de um AVA para níveis além de fronteiras previstas para esse tipo de ambiente, atingindo as áreas dos softwares sociais e dos MMORPGs $^{1}$.

\footnotetext{
${ }^{1}$ MMORPG (Multi Massive Online Role-Playing Game) é um jogo de interpretação de personagem online e em massa para múltiplos jogadores. Permite a milhares de jogadores a criação síncrona de personagens em um mundo virtual dinâmico na Internet.

V. $8 \mathrm{~N}^{\mathrm{o}}$ 3, dezembro, 2010
} 
O PLANETA ROODA, cuja temática é o espaço sideral, tem como finalidade possibilitar o trabalho coletivo na Internet com alunos e professores integrando funcionalidades que oportunizem a interação síncrona e assíncrona, o compartilhamento de arquivos e produções coletivas. Este ambiente é um software livre que foi desenvolvido por uma equipe interdisciplinar composta por pesquisadores das áreas de educação, programação e design, integrantes de um Núcleo de uma Universidade do Rio Grande do Sul.

\section{O Planeta ROODA}

O Planeta ROODA é um Ambiente Virtual de Aprendizagem que reúne uma plataforma (programação e interface) e uma rede de relações cognitivas, simbólicas e afetivas, sendo estas estabelecidas através dessa plataforma (BEHAR et al, 2007). Acreditase que esses ambientes possam ser utilizados tanto como suporte para aulas presenciais e semipresenciais quanto à distância. Dessa maneira, os AVA's caracterizam-se como uma ferramenta, um recurso para apoiar a aprendizagem, a comunicação, a colaboração e a coordenação das atividades em grupo.

Os pressupostos teóricos construtivistas adotados (Piaget, 1982; 1973), orientaram as escolhas e decisões no decorrer do desenvolvimento da plataforma. Dessa forma, o ambiente tem por objetivo promover o desenvolvimento de propostas desafiadoras de trabalho através das tecnologias digitais voltadas à comunicação e à educação; a interação entre crianças da própria escola e/ou de outras instituições; a expressão através da escrita e de imagens e a publicação de produções.

A primeira versão do Planeta ROODA começou a ser desenvolvida em 2005, com o objetivo de promover um espaço que possibilitasse o trabalho coletivo via web entre professores e alunos da Educação Infantil e Ensino Fundamental. De acordo com Schneider (2007), sua concepção se deu a partir de uma pesquisa ${ }^{2}$ desenvolvida em duas escolas do município de Porto Alegre e de levantamento realizado pela Internet. A partir das ideias coletadas nas escolas, o "espaço sideral" apresentou-se como tema recorrente entre as crianças da faixa etária entre 4 e 10 anos de idade. Os resultados dessa pesquisa sugeriram o conceito de space opera (novela espacial), gênero que abrange sagas cinematográficas como Star Wars e Star Trek e desenhos animados Cowboy Bebop e Star Blazers, como o mais adequado para a prototipagem do projeto (figuras 1 e 2).

\footnotetext{
2 Pesquisa realizada para a dissertação de mestrado de Daisy Schneider intitulada "Planeta Rooda: desenvolvendo arquiteturas pedagógicas para Educação Infantil e Anos Iniciais do Ensino Fundamental", defendida em 2007 pelo Programa de Pós-graduação em Educação pela Universidade Federal do Rio Grande do Sul.
}

V. $8 \mathrm{~N}^{\mathrm{o}}$ 3, dezembro, 2010 

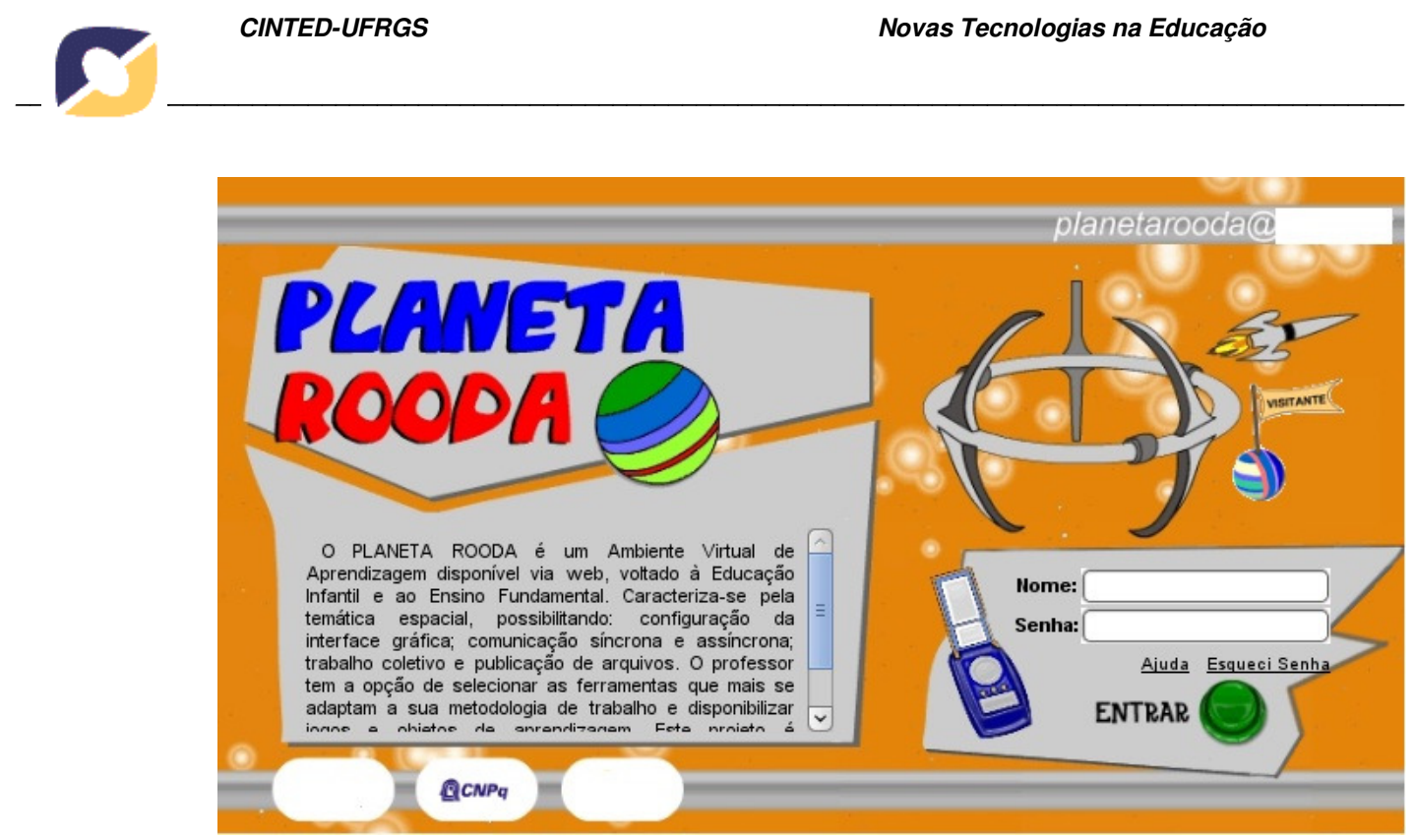

Figura 1- Tela de login do Planeta ROODA

Entre seus recursos, tanto alunos quanto professores tem acesso a ferramentas de comunicação (Comunicador, Bate-papo e Fórum), dispõem de um repositório de arquivos e trabalhos em grupo (Projetos), desenho (Planeta Arte), construção de jogos (Planeta Pergunta), perfil de usuário (Carteira), entre outras ferramentas que proporcionam a interação e o trabalho cooperativo, de acordo com a ação pedagógica do professor. De fácil navegação, utiliza símbolos de fácil compreensão nos botões de navegação, através dos quais, mesmo crianças não alfabetizadas podem navegar.

Para o gerenciamento das turmas, apenas usuários com nível de administrador podem habilitar outros usuários com níveis de professor ou aluno, abrindo ou não, a possibilidade de configuração das ferramentas por estes usuários.

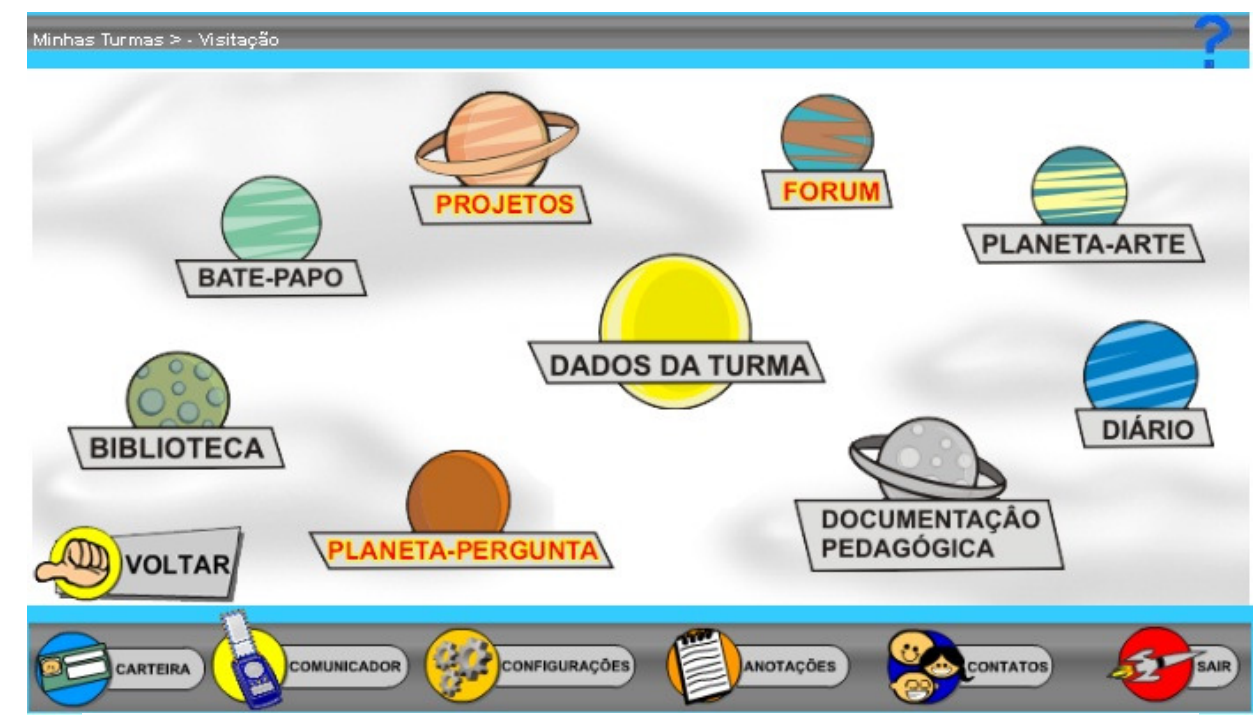

Figura 2 - Tela de acesso às funcionalidades do Planeta ROODA 
O ambiente foi desenvolvido como um software livre, sendo seu código, portanto, passível de livre modificação, tendo por objetivo permitir às instituições que o utilizam implementarem as modificações que correspondam às suas necessidades específicas. A execução do projeto foi realizada com o uso de linguagens de programação e banco de dados livres: PHP, JavaScript, AJAX e MySQL, tecnologias também presentes na versão 2.0 .

Foi utilizado e avaliado em diversos cursos de extensão destinados a professores de escolas públicas e particulares de Porto Alegre e região metropolitana. Com esses cursos, foi possível prospectar a opinião dos professores sobre a ferramenta, além da receptividade das crianças, quanto ao funcionamento do mesmo. Dessa maneira, diversas melhorias foram realizadas visando atender as opiniões dos participantes de todos os cursos em que utilizou-se o Planeta como ferramenta de apoio.

\section{Entrando na Web 2.0: O Planeta 2.0}

Devido aos avanços tecnológicos nos últimos anos, tanto no que diz respeito às plataformas de hardware (memórias maiores, processadores mais rápidos, internet banda larga, entre outros), quanto aos novos softwares de colaboração, podemos acompanhar uma evolução na web e em suas ferramentas. Com isso, surge uma segunda geração de comunidades e serviços baseados na plataforma Web, denominada Web 2.0. Mesmo que esse termo possua uma conotação de uma nova versão para a Web, ele não se refere à atualização nas suas especificações técnicas, mas a uma mudança na forma como ela é encarada por usuários e desenvolvedores. Nessa nova forma, as pessoas deixam de ser consumidoras de informação para se tornarem criadoras e distribuidoras de conteúdo e produzi-lo se torna tão fácil quanto era obtê-lo.

Segundo Primo (2007, p.1) "a web 2.0 é a segunda geração de serviços on-line e caracteriza-se por potencializar as formas de publicação, compartilhamento e organização de informações, além de ampliar os espaços de interação entre os participantes do processo". Dessa maneira, entram em cena as redes e softwares sociais, que proporcionam espaços de colaboração e troca de informação entre os usuários.

Os softwares sociais, que permitem ao usuário obter e publicar informações, trocar conhecimentos, realizar discussões, criar grupos ou comunidades virtuais, estão cada vez mais presentes na vida de crianças e adultos. Entre suas ferramentas, encontram-se fóruns, chats, troca de arquivos, álbuns de fotos, mensagens instantâneas, compartilhamento de hipertextos, vídeos, blogs, entre outros. Essas ferramentas oportunizam a comunicação e a construção social do conhecimento e possuem uma tecnologia que facilita o registro, a organização e a recuperação de informações (AMARAL, 2010).

Dessa forma o Planeta ROODA 2.0 objetiva, a partir dos conceitos da Web 2.0, produzir uma nova concepção de ambiente virtual de aprendizagem baseada na interação, socialização e na construção compartilhada do saber, ultrapassando o paradigma do simples repositório de materiais didáticos. Apropria-se, também, de recursos digitais similares aos aplicados em plataformas da atualidade como o Facebook, Second Life, entre outros. 


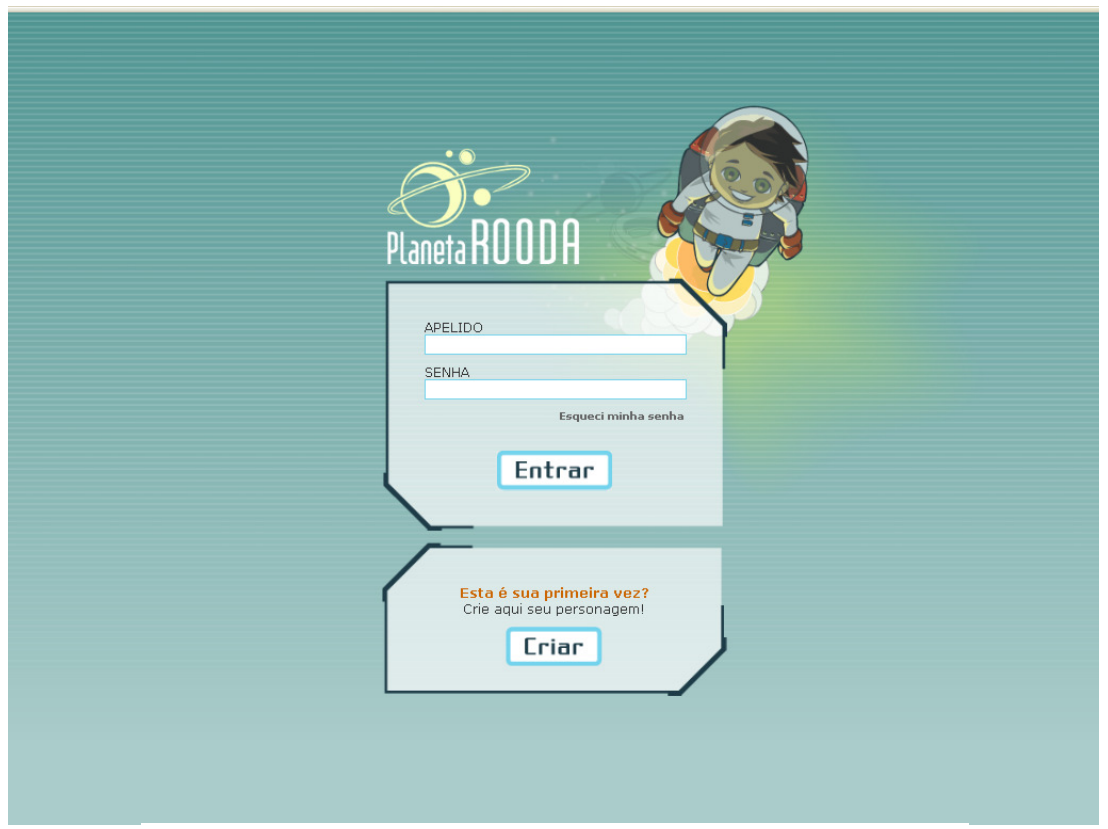

Figura 3 - Tela de login do Planeta ROODA 2.0

A temática espacial presente na primeira versão do ambiente foi mantida no Planeta 2.0 (figura 3). A grande novidade da nova versão é a forma como se dá a interação do aluno com os demais usuários e funcionalidades: as telas estáticas, vinculadas por imagens que proporcionavam a navegação, deram lugar a um cenário, desenvolvido em Flash ${ }^{3}$, baseado no espaço - um planeta - no qual os participantes do ambiente são representados por avatares $^{4}$ que caminham em todas as direções; a interação alcança um paralelismo com a realidade sem precedentes na versão anterior: se então os usuários já podiam se comunicar em tempo real, na nova versão a criança não só "conversa" instantaneamente com seu colega, como pode "visualizá-lo" de acordo com a imagem que ele faz de si mesmo, projetada nos atributos do avatar.

Além do avatar, cada usuário dispõe de um "sistema", o qual pode ser configurado de forma a imprimir uma identificação ainda maior, transpondo os limites do avatar e abrangendo o meio que o cerca, através do livre arranjo de árvores, postes, arbustos, construções e demais elementos do cenário. A criação de "cenários" individuais para cada participante foi inspirada na Teoria dos Multiversos (Melo, 2003), que prevê a existência de universos virtuais (mundos paralelos) dentro de outros universos virtuais, no qual as autorizações são herdadas. No caso da implementação do Planeta ROODA 2.0, tem-se a figura do administrador, que é o usuário que dá origem aos demais. É a partir dele que se dá o controle e a personalização dos ambientes. Através do Módulo de Construção, ele insere elementos contendo as funcionalidades do Planeta, dando corpo ao seu ambiente. A partir de então, o administrador pode criar novos universos vinculados ao seu - o universo de origem -, que também terão seus próprios administradores, por ele delegados. Os novos administradores, por sua vez, também poderão personalizar os seus ambientes bem como

\footnotetext{
${ }^{3}$ Tecnologia de gráficos vetoriais da Adobe para criação de animações interativas que podem ser executadas em um navegador de internet.

${ }^{4}$ Avatar é a representação virtual de um usuário de computador ou de seu alter ego.

V. $8 \mathrm{~N}^{\mathrm{o}}$ 3, dezembro, 2010
} 
criar novos sistemas, com novos administradores e assim por diante. Os administradores tem autorização para interferir em todos os universos criados a partir do dele, mas nunca, a menos que ganhem tal permissão, no universo a partir do qual o seu foi gerado. Os demais níveis de usuários possíveis são: coordenador, supervisor, professor e aluno, também com permissões herdáveis, ou seja, o coordenador pode alterar as ações do supervisor, que pode alterar as do professor, que, por seu turno, pode fazer o mesmo em relação ao aluno.

\section{Explorando o Planeta 2.0}

A principal e mais perceptível novidade do Planeta 2.0 em relação ao seu antecessor é a interface pela qual o usuário desvenda o Ambiente (figura 4). A tela que dava acesso às funcionalidades, através de links representados por imagens, foi substituída por um terreno virtual no qual o usuário, representado pelo seu avatar, locomove-se entre os elementos que compõem o cenário - árvores, arbustos, prédios -, podendo ingressar nas funcionalidades representadas por pequenas casas identificadas - ou conversar, através do Comunicador, com os demais usuários que estiverem naquele sistema.

Ao transformar uma interface estática - uma lista de links representados por imagens - em um terreno planejado para proporcionar uma experiência coletiva, simultânea e em tempo real entre os usuários, o Planeta 2.0 postula espaço entre as aplicações conhecidas como mundos virtuais, gênero do qual Second Life é o mais conhecido expoente. Tal mudança tem por objetivo estabelecer uma versão do Ambiente em sintonia com os novos paradigmas da web, sensível às demandas e aspirações dos internautas familiarizados com as redes sociais, tornando-o mais atraente para esse público, do qual as crianças constituem parcela significativa.

O Comunicador, funcionalidade já existente no Planeta ROODA, agora faz parte do ambiente no qual os avatares interagem. Na versão anterior, a ferramenta era acessada de forma semelhante a um comunicador instantâneo, através de uma janela que se abria dentro da plataforma, exibindo os usuários on-line e notificando sobre as mensagens recebidas e permitindo respostas em tempo real. No Planeta 2.0, o Comunicador está integrado ao ambiente e ao próprio avatar. As "conversas" são exibidas sobre a representação do usuário na tela e aparecem para todos que estiverem conectados ao sistema em que ele se encontra, possibilitando que as conversas coletivas e as interações entre alunos surjam de forma muito mais espontânea - sem que seja necessário abrir intencionalmente uma janela e procurar algum contato on-line. Um dos próximos aperfeiçoamentos a serem implementados na funcionalidade é a inclusão de um balão sobre o avatar - como nas histórias em quadrinhos - contendo as mensagens que o aluno escreve para se comunicar com os colegas. Com isso, busca-se ressaltar que o texto em questão nada mais é do que a "fala" do usuário. 

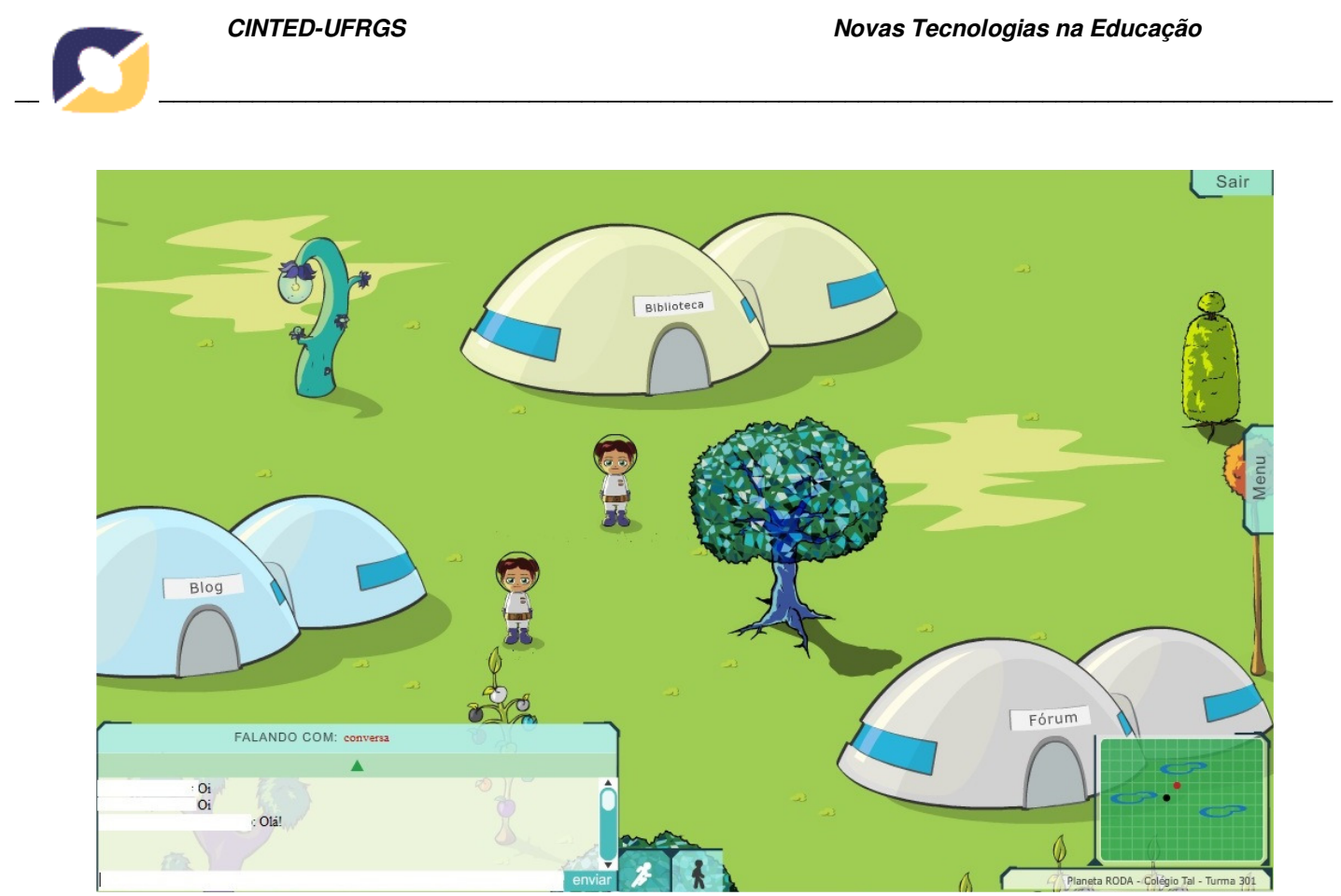

Figura 4 - Tela com avatares utilizando o comunicador em um sistema

Uma das novas ferramentas propostas pelo Planeta 2.0 é o Blog, com a finalidade principal de possibilitar aos usuários desenvolverem e divulgarem os trabalhos solicitados pelos professores. Para tanto, os alunos contarão com blogs individuais e coletivos, sendo sua visitação aberta tanto aos usuários do Ambiente, quanto ao público em geral, através de um link que permite acesso externo, o que permitirá a familiares e amigos acompanharem o desenvolvimento do aluno. Muito embora a proposta inicial do blog seja a elaboração de tarefas escolares, espera-se que as crianças utilizem-no a fim de apresentar suas idéias e impressões sobre temas de seu interesse e, no caso do diário coletivo, dos seus colegas. Além de criar um canal fértil para a troca de experiências, tanto autor-autor quanto autorvisitante, vislumbra-se na funcionalidade um artífice de estímulo ao livre desenvolvimento de ideias e concepções individuais sobre as mais diversas temáticas acompanhado, por consequência desse exercício, de uma crescente fluência na argumentação escrita.

Além do Blog, o Planeta 2.0 contará com funcionalidades já presentes na versão original, entre as quais se destacam:

- Biblioteca: ambiente no qual os alunos trocam conteúdos interessantes encontrados na Web relacionados a temas que estão sendo estudados em sala de aula;

- Fórum: interface que permite a interação assíncrona entre os alunos, bastante interessante para a discussão de assuntos específicos;

- Planeta Arte: ferramenta que permite a criação e o compartilhamento de desenhos entre os alunos. A versão que está em desenvolvimento prevê a possibilidade de desenhos coletivos, fortalecendo a interação entre os alunos.

- Portfólio do Professor: espaço para o professor montar o seu planejamento e registrar suas impressões.

- Planeta Pergunta: funcionalidade que permite aos alunos criarem perguntas sobre assuntos do seu interesse. 


\section{Considerações finais}

O Planeta ROODA 2.0 está sendo validado em um Curso de Extensão, "Planejamento Criativo e Pesquisa: em jogo o conhecimento do professor e do aluno", ofertado pela Professora Darli Collares pela Faculdade de Educação da UFRGS. Com o objetivo de abranger um público diversificado, essa ação de extensão foi divulgada em jornais, no site da UFRGS e em escolas, sem um público-alvo especificado. Busca-se com essa ação, proporcionar debates acerca das implicações que estão sendo apresentadas com as mudanças constantes dessas novas infâncias. Dessa maneira, a ferramenta disponibiliza, aos professores desta geração, um material didático-pedagógico digital buscando auxiliar práticas pedagógicas que contemplem essa ciberinfância.

Contando com mais de 50 inscritos, o público é caracterizado por professores de Educação Infantil, das séries iniciais e finais do Ensino Fundamental, bem como estudantes de licenciatura em diferentes áreas do conhecimento. Para a validação do Planeta ROODA, estabeleceu-se o critério de que os participantes deveriam ter regência de classe, já que implicaria no uso da ferramenta com seus alunos. Entre esses, sete professores se disponibilizaram a utilizá-lo em suas aulas contando, também, com o acompanhamento dos ministrantes do curso para desenvolvimento de atividades.

Para analisar como o Planeta pode contribuir no desenvolvimento de uma prática pedagógica, serão pesquisadas as análises das ações dos principais personagens do processo educativo: professores e alunos em um ambiente de trocas e aprendizagem. Dessa forma, pretende-se analisar como os mesmos compreenderão os princípios teóricos da criatividade com a sua ação docente, além do processo de criatividade da turma no ambiente escolar.

Através do uso do Planeta ROODA 2.0 serão investigadas as diferentes formas de utilização por alunos e professores, bem como o fluxo da comunicação entre os usuários, a fim aperfeiçoar seu desempenho e propor novas funcionalidades. Destaca-se que o desenvolvimento de um AVA é contínuo, abarcando ajustes no sistema e a implementação de novos recursos. Assim, pretende-se pesquisar as propostas pedagógicas dos professores e como isso se reflete no uso do ambiente pelas crianças, visando investigar a sua aprendizagem através de AVAs. Com a implementação dessas ferramentas, pretende-se disponibilizar o Planeta 2.0 na web, para acesso em rede ou por download.

\section{Referências:}

AMARAL, C. B. Desafio de Ciberinfância: A Composição de Práticas Pedagógicas Utilizando Artefatos Tecnológicos. Programa de Pós-graduação em Educação. Universidade Federal do Rio Grande do Sul, 2010.

BEHAR, P. A.; LEITE, S. M.; BORDINI, S.; SOUZA, L. B.; SIQUEIRA, L. G. Avaliação de Ambientes Virtuais de Aprendizagem: o Caso do ROODA na UFRGS. Revista Avances en Sistemas e Informática. Medellín. v. 4, p. 81-100, 2007.

MELO, Amanda Meincke. Uma Abordagem Semiótica para o Design de Portais Infantis com a Participação da Criança. Campinas,S.P, 2003. 
PIAGET, J. A Representação do Mundo na Criança. Rio de Janeiro: Record, 1982.

PIAGET, J. Estudos Sociológicos. Rio de Janeiro: Forense, 1973.

PRIMO, A. O Aspecto Relacional das Interações na Web 2.0. E- Compós (Brasília), v. 9, p. 1-21, 2007.

SCHNEIDER, D. Planeta ROODA: Desenvolvendo Arquiteturas Pedagógicas para Educação Infantil e Anos Iniciais do Ensino Fundamental. Programa de Pós-graduação em Educação. Universidade Federal do Rio Grande do Sul, 2007. 